\title{
Investigations of optical and surface properties of Ag single thin film coating as semitransparent heat reflective mirror
}

\author{
J. Domaradzki ${ }^{1, *}$, D. Kaczmarek ${ }^{1}$, M. Mazur ${ }^{1}$, D. Wojcieszak $^{1}$, J. Halarewicz ${ }^{2}$, \\ S. GLODEK ${ }^{2}$, P. DOMANOWSKI ${ }^{3}$ \\ ${ }^{1}$ Faculty of Microsystem Electronics and Photonics, Wroclaw University of Technology, Wyspianskiego 27, \\ 50-370 Wroclaw, Poland \\ ${ }^{2}$ BOHAMET S.A., Torunska 2, 86-005 Ciele, Poland \\ ${ }^{3}$ Faculty of Mechanical Engineering, University of Technology and Life Sciences in Bydgoszcz, Kaliskiego 7, \\ 85-796 Bydgoszcz, Poland
}

\begin{abstract}
The paper presents results of optical and surface morphology investigations of semitransparent silver single thin films deposited on glass substrate in relation to their heat radiation treatment. The thickness of $15 \mathrm{~nm}$ for the silver thin films was selected using computer designing of optical spectra and the films were deposited using electron beam evaporation process. Optical transmission and reflection were investigated for as deposited samples and after exposition to heat radiation from quartz-halogen lamp. The changes in the optical spectra were observed which suggested degradation of deposited heat mirrors. Structure and surface morphology studies performed using scanning electron microscopy, X-ray photoelectron spectroscopy and atomic force microscopy allowed us to conclude about formation of nanometric silver islands, regularly distributed over the surface of the glass substrate after exposure to heat treatment.
\end{abstract}

Keywords: optical coating; optical properties; heat reflective mirror; surface analysis

(C) Wroclaw University of Technology.

\section{Introduction}

Metallic thin films, such as silver, gold etc. exhibit high optical reflection over a wide optical radiation spectra that make them suitable for the use as optical mirrors. For this purpose the thin film should be continuous what can be achieved when a coating is at least $50 \mathrm{~nm}$ thick. Another requirement is very flat and smooth surface in order to achieve a high directional reflection. However, application of non-continuous thin films can benefit from their unique properties: the films may exhibit semi-transparency, while still preserve their ability to light reflection. For example, such films have already found application in the construction of socalled low emissivity coatings applied in architectural glass windows [1].

In this paper, considerations of application of single and semitransparent $\mathrm{Ag}$ thin films in

*E-mail: jaroslaw.domaradzki@pwr.edu.pl the construction of optical heat mirror has been discussed. The hot mirror is in fact a kind of optical thin-film-low-pass filter that, depending on application, should be characterized by e.g. excellent transmission in the visible range while in the infrared range it should reflect as much energy as possible. One of possible applications of such mirrors could be in the construction of fire protective barrier that can be a part of a window, wall, door that could block propagation of fire and heat transfer for a specified time. The heat generated by fire is related to radiation of electromagnetic waves in the infrared from near- to long-wavelength range. The principle of operation of such optical barrier relies on using destructive and constructive interference effects at the interfaces of the air (surrounding environment) - metal thin film and metal thin film glass substrate.

Investigations presented in this paper cover determination of optical and surface morphology studies of thin Ag coatings before and after 
exposition of prepared semitransparent mirrors to heat radiation.

\section{Designing of optical thin film heat mirrors}

Fire resistant optical barrier should be composed of materials (layers) that allow reflecting optical radiation in the infrared range while still preserve excellent transmission in the visible range. The principle of operation of optical thin film filters consists in using destructive or constructive interferences of light reflected at a particular wavelength from the interface between thin film - substrate and thin film - environment [2].

Metals are well known glazing materials that block radiant heat, however, in general they are not transparent in the visible spectral range in the solid state form. Fig. 1 shows designed exemplary spectral characteristics of transmission $(\mathrm{T})$ and reflection $(\mathrm{R})$ coefficients of silver with different thickness and in Fig. 2 the dependence of $T$ and $R$ on thin film thickness for selected wavelength of $550 \mathrm{~nm}$ is presented. All theoretical curves were designed using Film Star Design software [3]. Designing of optical coatings is an efficient way to predict the optical properties of the coatings. Ag thin films with the thickness up to $10 \mathrm{~nm}$ seem to be transparent enough in the visible range (Fig. 1). Simultaneously, their glazing property in the infrared range is better with increasing thickness (Fig. 2). The best designing results (a compromise between reflection and transmission) for a single $\mathrm{Ag}$ thin films were obtained for the thin film with $15 \mathrm{~nm}$ thickness (Fig. 2).

\section{Experimental}

For the purpose of further investigations, the silver thin film with the thickness of $15 \mathrm{~nm}$ were evaporated using a typical box coater equipped with electron beam evaporation system [4]. Prior to deposition the $400 \mathrm{~L}$ vacuum chamber was evacuated with rotary and diffusion pumps to the base pressure of $1.5 \times 10^{-3} \mathrm{~Pa}$. The silver granules (99.99 at. \% purity) were placed in a tungsten boat
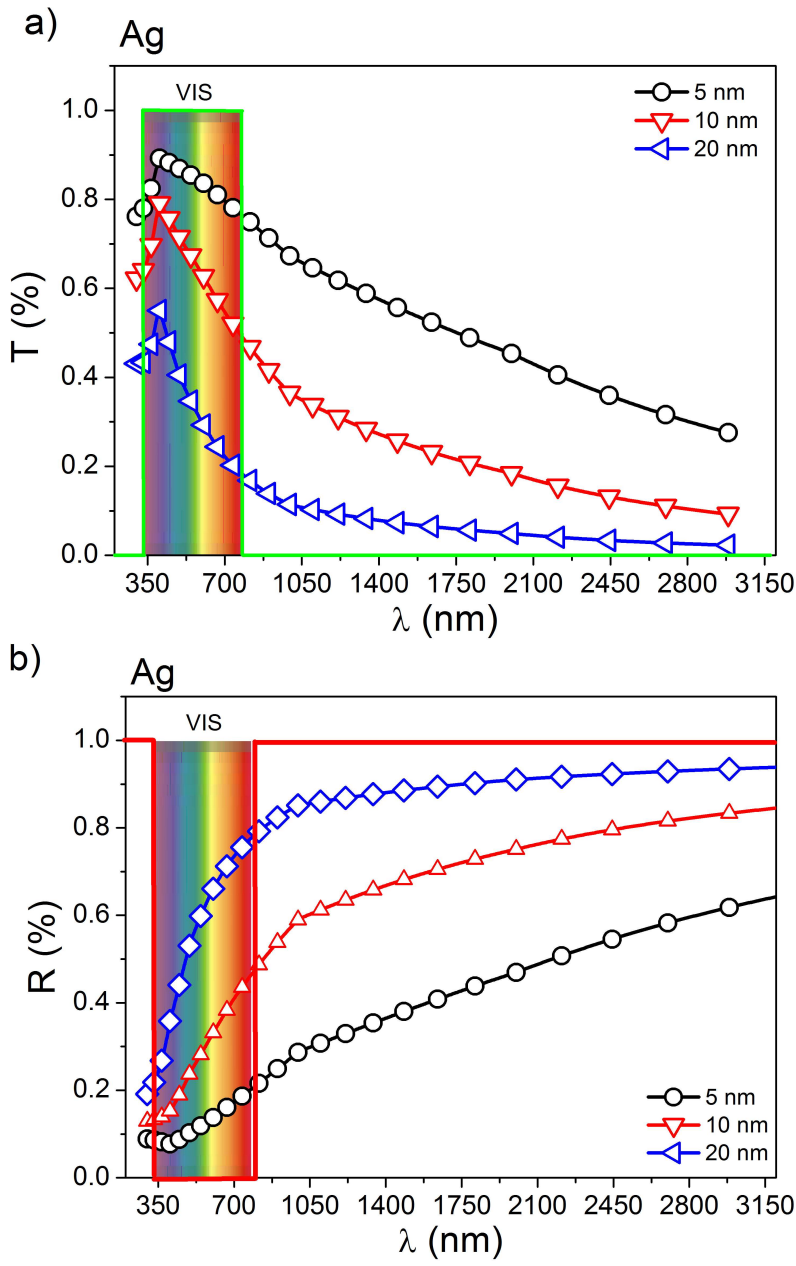

Fig. 1. Spectral characteristics of: (a) transmission and (b) reflection coefficients designed for $\mathrm{Ag}$ thin films with different thicknesses.

and the electron beam parameters were $7 \mathrm{kV}$ acceleration voltage and $15 \mathrm{~mA}$ the beam current. The distance form the evaporation crucible to the substrates (plane glass $100 \times 100 \mathrm{~mm}$ and $4 \mathrm{~mm}$ thick) was $50 \mathrm{~cm}$ and the substrates were rotated during deposition at $10 \mathrm{rpm}$ speed. The thickness of deposited thin films was controlled by a FTC-2800 (Kurt J. Lesker Co.) quartz monitor.

Optical reflection and transmission spectra were collected using a coupled DH-2000-BAL deuterium-halogen lamp as an excitation light source, $30 \mathrm{~mm}$ integration sphere and two Ocean Optics spectrophotometers: QE65000 type for 200-900 nm range and NIR 256-2.1 type for 900$2100 \mathrm{~nm}$ range. 


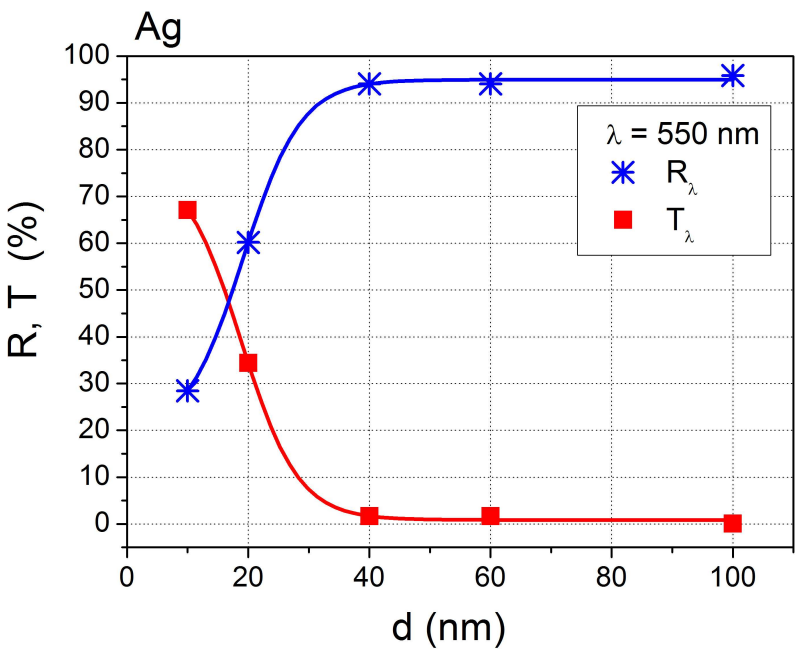

Fig. 2. Dependence of transmission and reflection coefficients on thin film thickness estimated for $\lambda=550 \mathrm{~nm}$.

Quartz-halogen lamp was used to generate heat radiation and the samples were exposed from the distance of $300 \mathrm{~mm}$. Temperature of the samples during exposition to heat was controlled by standard K-type thermocouples and it was recorded over the exposition time using Agilent 34970A unit equipped with Agilent 34901A 20 channel multiplexer.

The surface morphology and elemental composition of thin films were investigated using a FESEM FEI Nova NanoSEM 230 scanning electron microscope (SEM) equipped with energy dispersive spectrometer (EDS). Surface topography was investigated with the aid of UHV VT AFM/STM Omicron atomic force microscope (AFM) operating in ultra-high vacuum conditions in contact mode. The root mean square (RMS) surface roughness was calculated from five different AFM images for as-deposited and annealed samples. For analysis of experimental data WSxM ver. 5.0 software was used [5]. X-xay Photoelectron Spectroscopy (XPS) measurements were performed to determine the chemical states of each element on the sample surface. Specs Phoibos 100 MCD-5 (5 single channel electron multiplier) hemispherical analyser using a Specs XR-50 X-ray source with $\operatorname{MgK} \alpha(1253.6 \mathrm{eV})$ beam was used. Measurements results were analysed with the aid of CasaXPS software. All spectra were calibrated with respect to the binding energy of adventitious $\mathrm{C} 1 \mathrm{~s}$ peak at $284.8 \mathrm{eV}$.

\section{Results}

\subsection{Optical and temperature-time depen- dent studies}

Fig. 3 presents a comparison of designed and measured transmission and reflection spectra for the as-deposited thin film. Measurement spectra and designed theoretical curves show a good agreement.

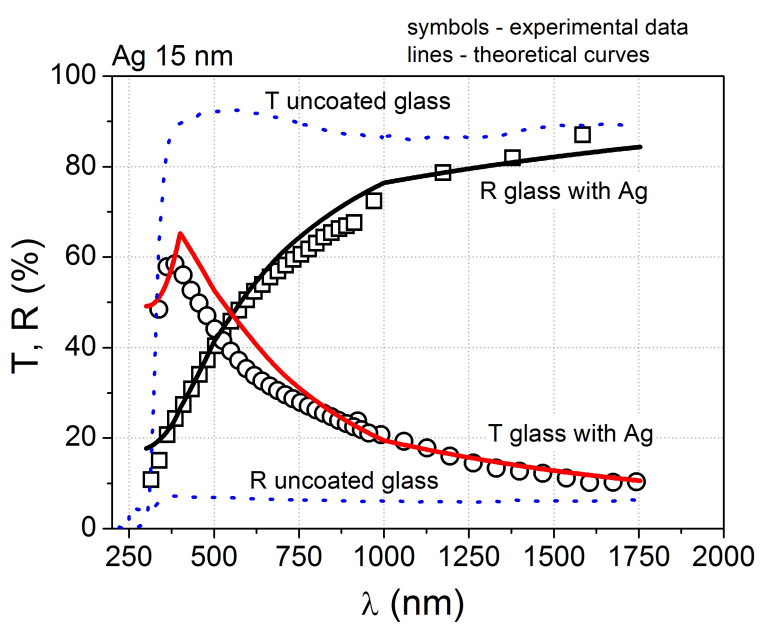

Fig. 3. Transmission and reflection characteristics of $15 \mathrm{~nm}$ silver thin films deposited on glass by electron beam evaporation. Theoretical curves were designed using Film Star Design software.

The temperature-time dependent chart was prepared using measurement of the temperature at the back surface of the sample covered with $15 \mathrm{~nm}$ thick silver thin film. For comparison, at the same time the temperature at the surface of the reference - uncoated glass has also been registered and plotted in Fig. 4.

Performed investigations showed much less temperature at the back surface of the glass coated with $15 \mathrm{~nm}$ silver thin film during about first 8 minutes of experiment or to the temperature increase to about $110^{\circ} \mathrm{C}$, as it was indicated by measurement performed using the reference sample. Therefore, the heat transfer from the glass side protected with 
deposited $15 \mathrm{~nm}$ silver thin film was blocked. However, after ten minutes the temperature characteristics indicated rapid increase in temperature that was similar to the uncoated glass.

In Fig. 5 transmission and reflection characteristics of the sample with Ag heat mirror after exposition to heat radiation is presented. These results show that after exposition to heat radiation the $15 \mathrm{~nm} \mathrm{Ag}$ thin film completely lost its reflective properties in the infrared range (Fig. 3).

\subsection{Surface morphology studies}

SEM images (Fig. 6a) revealed that after the deposition, the sample surface was very smooth, crack free and homogenously covered with Ag thin film. In turn, after exposition to heat radiation the surface of the coating was covered with particles with round shape (Fig. 6b). Diameter of these particles was in the range of ca. $20 \mathrm{~nm}$ to $80 \mathrm{~nm}$.

Additional EDS measurements were performed in two different places on the sample surface, marked in Fig. 7. In the area of $1^{\text {st }}$ point these studies revealed that it consisted mainly of silver $\left(\mathrm{AgL}_{\alpha}\right)$ and silicon $\left(\mathrm{SiK}_{\alpha}\right)$. Therefore, it can be concluded that visible particles are pure silver, while silicon signal is related to the $\mathrm{SiO}_{2}$ substrate. In turn, measurement in the $2^{\text {nd }}$ point area showed that this peak is related to silicon species only.

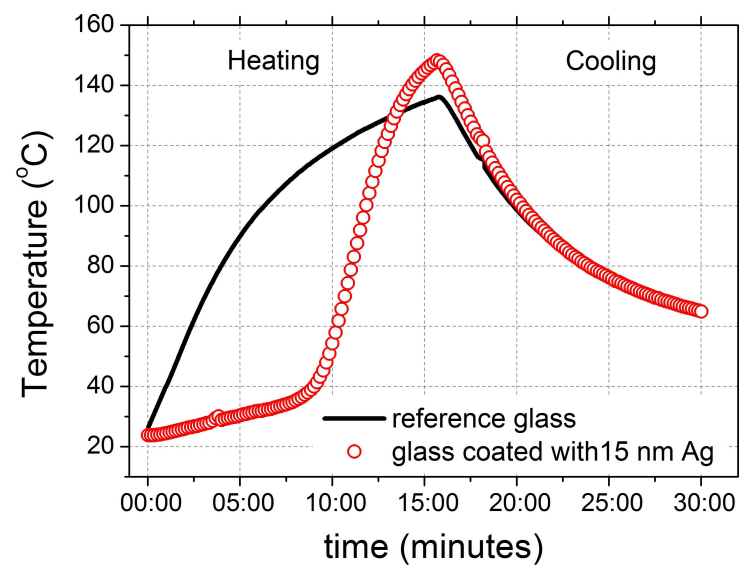

Fig. 4. Temperature changes measured at the back surface of a reference and $15 \mathrm{~nm} \mathrm{Ag}$ coated glass under exposition to heat radiation from quartzhalogen lamp.

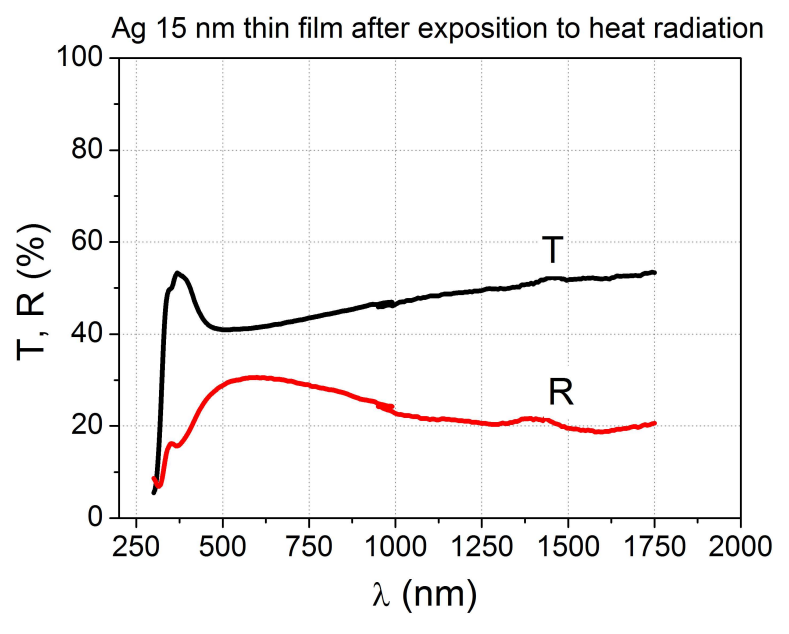

Fig. 5. Transmission and reflection spectra of the $15 \mathrm{~nm}$ $\mathrm{Ag}$ thin film coating after exposition to heat radiation.
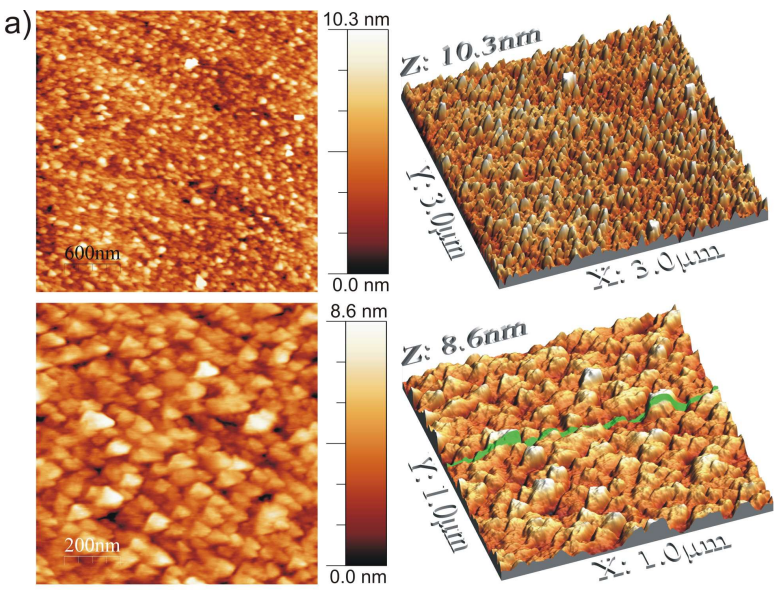

b)
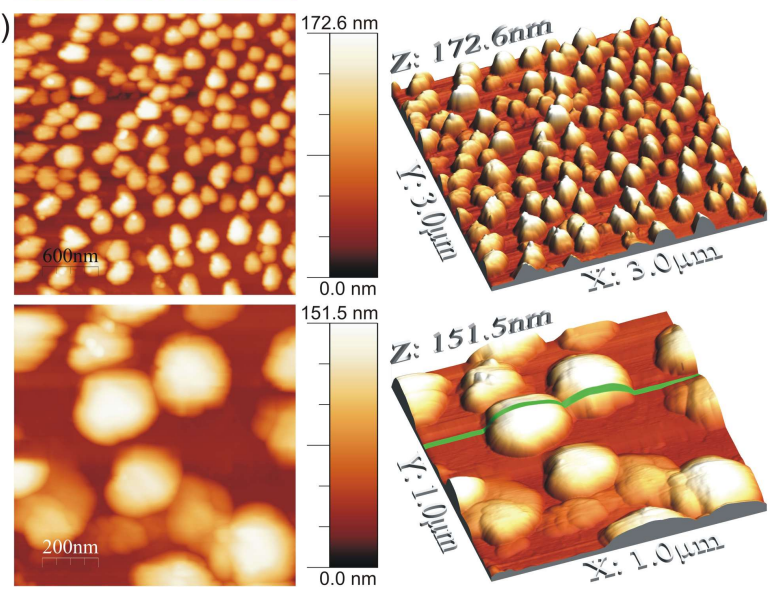

Fig. 6. SEM images of the surface of: a) as-deposited and b) annealed $15 \mathrm{~nm} \mathrm{Ag}$ thin films prepared by electron beam evaporation. 
Therefore, in this area only pure, uncoated $\mathrm{SiO}_{2}$ substrate is present. Based on performed SEM studies it might be concluded that the observed degradation of optical (Fig. 5) and protective (Fig. 4) properties of the deposited silver thin film were caused by agglomeration of silver into round shaped islands.
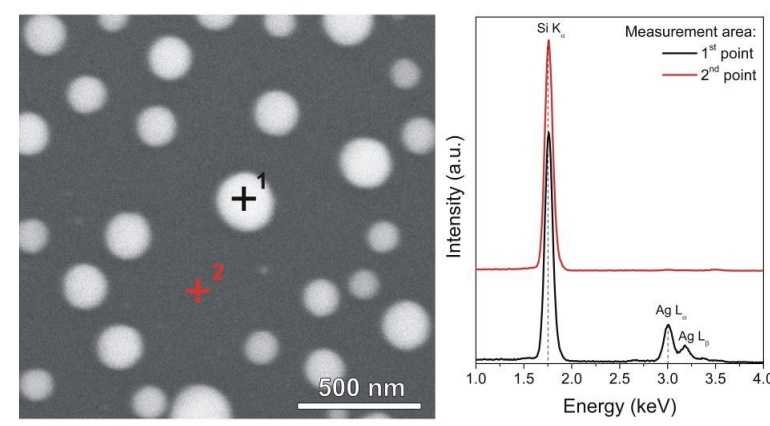

Fig. 7. EDS spectra of annealed Ag thin films taken from marked areas.

To extend the information about the surface topography of deposited and heated thin films, AFM measurements were additionally performed. In Fig. 8 two- and three-dimensional images of the surface with various magnifications are shown. For the as-deposited coating its surface was crack free and composed of very small grains with maximum height of ca. $10 \mathrm{~nm}$. On the other hand, the heated thin films were covered by round silver particles with rather homogenous shape and dimensions of ca. several tens to few hundred nanometers. Maximum height of these islands was ca. $170 \mathrm{~nm}$. In view of obtained images it can be concluded that AFM measurements confirmed the results obtained by SEM method.

In Fig. 9 the height distribution of grains and cross-section topographies of the surface of asdeposited and heated $\mathrm{Ag}$ thin films are additionally presented. In the case of as-deposited coatings the height distribution of grains is rather symmetric, which can testify about homogenous dimension of Ag grains. Most of these grains have the height in the range of 4 to $6 \mathrm{~nm}$ and calculated RMS surface roughness is equal to $1.7 \mathrm{~nm}$. For the heated sample the height distribution of the grains is not symmetric and two various ranges of grains height a)

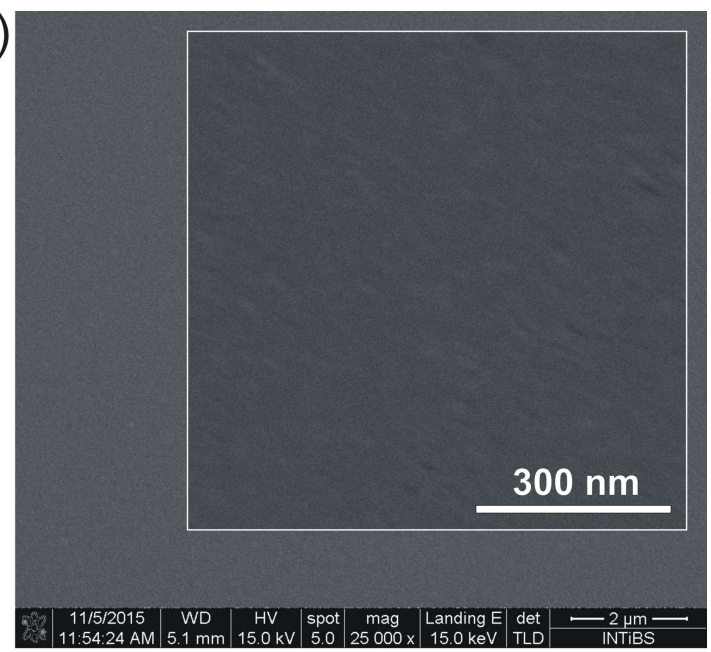

b)

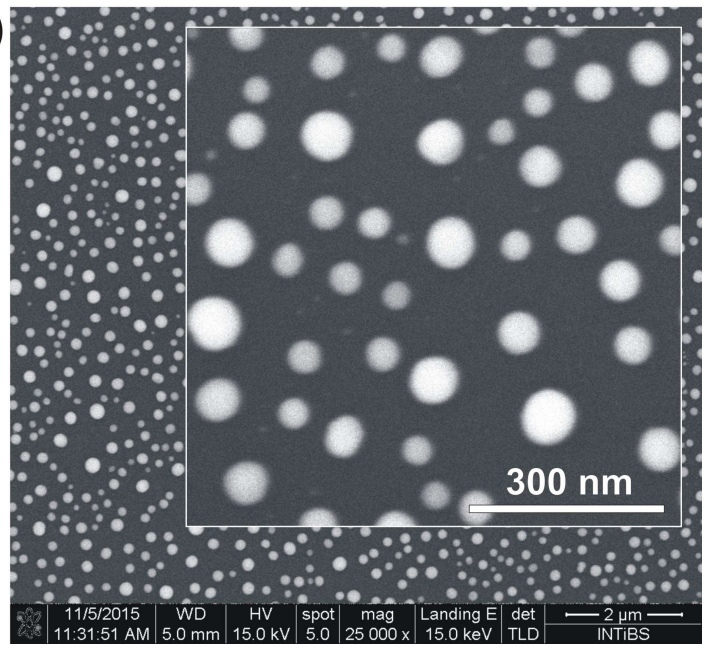

Fig. 8. AFM images taken at different magnifications for: a) as-deposited and b) heated $\mathrm{Ag}$ thin films.

can be distinguished, i.e.: 10 to $35 \mathrm{~nm}$ and 40 to $120 \mathrm{~nm}$, from which the first one is more dominant. The calculated RMS roughness is higher than for the as-deposited thin film and equal to $39.5 \mathrm{~nm}$.

In Fig. 9b the cross-section topography of the surface of the as-deposited and annealed coatings is compared. It is clearly seen that the surface roughness is significantly lower and surface homogeneity is greater for the as-deposited sample.

\subsection{Surface states studies}

The chemical states of silver, oxygen and silicon on the surface of prepared thin films were determined by XPS measurements (Fig. 10). 

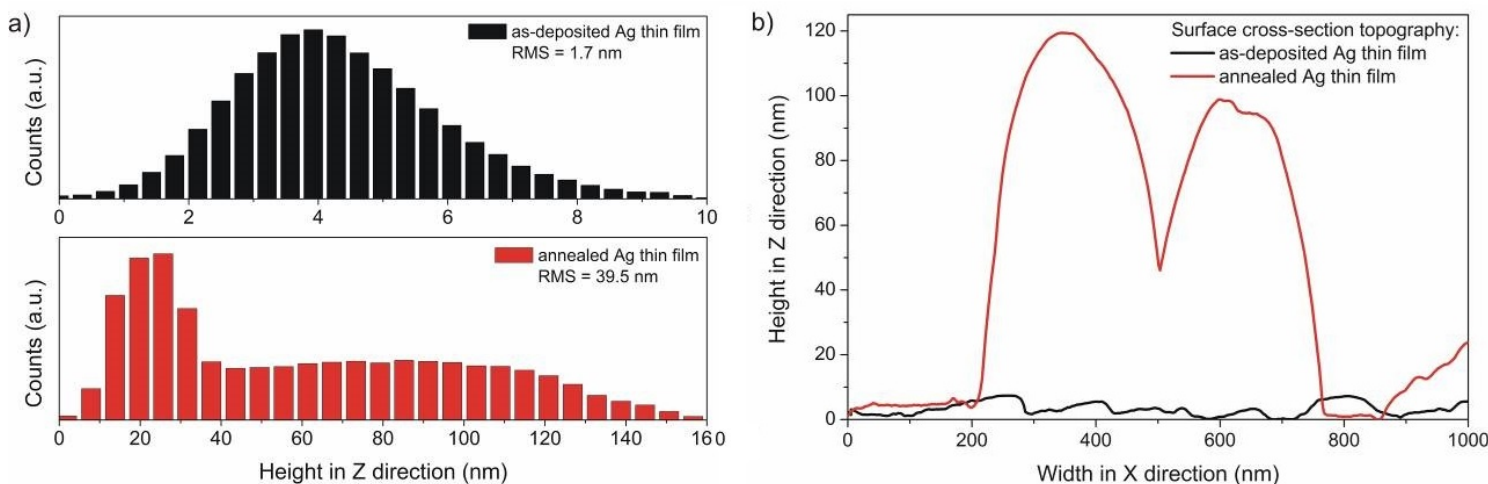

Fig. 9. AFM analysis results: a) height distribution of grains size in $\mathrm{Z}$ direction and b) cross-section topography of as-deposited and heated Ag thin films.
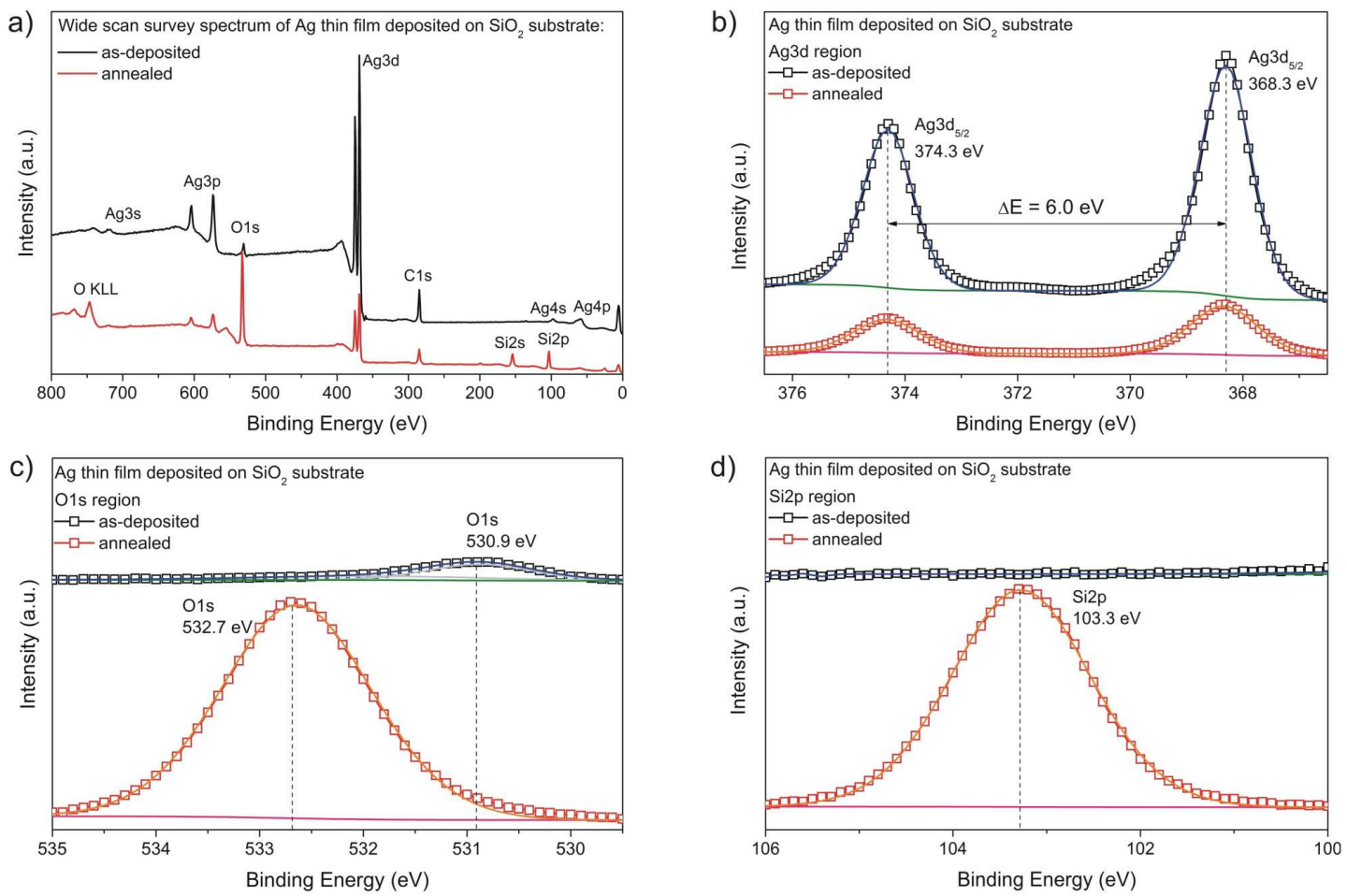

Fig. 10. XPS spectra of as-deposited and annealed Ag thin films: a) wide scan survey spectrum, b) Ag3d, c) O1s and d) $\mathrm{Si} 2 \mathrm{p}, \mathrm{Ag} 3 \mathrm{~s}$ regions.

Additionally, the full range spectrum was also collected to check if the surface was uncontaminated by chlorine or sulfur, which are common contaminants on silver surfaces due to the gases that contain them [6]. In both cases, for the asdeposited and annealed samples, no $\mathrm{Cl}$ or $\mathrm{S}$ related peaks were found in the wide scan survey spectrum. However, some clearly visible changes were noticed. For the as-deposited thin film, except $\mathrm{Ag}$ related peaks also $\mathrm{C} 1 \mathrm{~s}$ and $\mathrm{O} 1 \mathrm{~s}$ peaks were found, while for the annealed sample additional $\mathrm{Si} 2 \mathrm{p}$ and $\mathrm{Si} 2 \mathrm{~s}$ peaks were revealed. For the asdeposited coating $\mathrm{C} 1 \mathrm{~s}$ peak is higher than for the heated sample, which can be explained by removal of carbon/carboxyl groups from the surface during heating. Significantly more intensive O1s peak 
for the heated sample is related to the $\mathrm{SiO}_{2}$ substrate, which is present on the surface between the silver islands.

For both samples the fitting of $\mathrm{Ag} 3 \mathrm{~d}$ spectrum revealed a doublet of $\mathrm{Ag} 3 \mathrm{~d}_{5 / 2}$ and $\mathrm{Ag} 3 \mathrm{~d}_{3 / 2}$ separated by $6 \mathrm{eV}$ that is related to the $\mathrm{Ag}-\mathrm{Ag}$ metal bonds. In both cases the position of each silverrelated peaks is in the same place. Their separation energy proves the presence of metallic silver at the thin film surface [6-8].

O1s peak is a bit shifted for the heated sample. For the as-deposited coating, oxygen is bonded to carbon or carboxyl groups, which are present at the surface while for the annealed sample oxygen is bonded to silicon, as the binding energy of this peak is related to $\mathrm{SiO}_{2}[6,7]$.

As it was already shown in full range spectrum, for the as-deposited thin film the peak related to $\mathrm{Si} 2 \mathrm{p}$ is not present, while for the heated sample it is strong and related to $\mathrm{SiO}_{2}$ substrate $[6,7]$.

\section{Conclusions}

In the paper, investigations of protective properties of $15 \mathrm{~nm}$ Ag thin film used as an optical mirror against heat radiation have been described. As it was concluded from the performed investigations, heating of the films caused non-reversible changes in their optical spectra and loosing protective properties. Extended surface morphology and surface states studies allowed us to find that the $\mathrm{Ag}$ thin film after exposition to heat radiation was transformed into Ag nano-islands, randomly distributed over the glass substrate surface. The sizes of observed islands determined from SEM and AFM investigations ranged mainly between 10 to $35 \mathrm{~nm}$ and 40 to $120 \mathrm{~nm}$. XPS studies did not reveal any typical contaminations, as for example chlorine or sulfur, at the samples surface.

\section{Acknowledgements}

This work was financed from the sources granted by the NCBiR in the years 2013-2016 as an Applied Research Program No. PBS2/A5/33/2013.

\section{References}

[1] Grose P., Hertling R., Muggenburg T., J. NonCryst. Solid, 218 (1997) 38.

[2] MACLEOD A. H., Thin-film optical filters, IOP London, 2001.

[3] FilmStar Design Software, FTG Software Inc.

[4] Wojcieszak D., Poniedziałek A., Mazur M., DoMARADZKi J., KACZMAREK D., DorA J., to be published in Mater. Sci.-Poland, 4 (2016).

[5] Horcas I., Fernandez R., Gómez-Rodriguez J.M., Colchero J., Gomez-Herrero J., BAro A.M., Rev. Sci. Instrum., 78 (2007) 013705.

[6] CRIST B.V., Handbook of The Elements and Native Oxides, XPS International Inc. Iowa, USA, 1999.

[7] Moulder J., Stickle W., Sobol P., Bomben K., Handbook of X-ray Photoelectron Spectroscopy, Physical Electronics Inc., USA, 1995.

[8] Wojcieszak D., Mazur M., Kaczmarek D., MAZUR P., SZPONAR B., DOMARADZKI J., KĘPIŃSKI L., to be published in Mat. Sci. Eng. C, (2016) 